\title{
Mannitol Reduces the Hydrostatic Pressure in the Proximal Tubule of the Isolated Blood-Perfused Rabbit Kidney during Hypoxic Stress and Improves Its Function
}

\author{
Robbert Bipat $^{\mathrm{a}}$ Paul Steels $^{\mathrm{b}} \quad$ Yves Cuypers $^{\mathrm{b}} \quad$ Jerry R. Toelsie ${ }^{\mathrm{a}}$

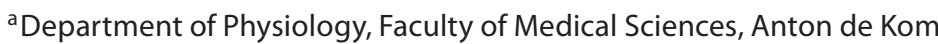 \\ University of Suriname, Paramaribo, Suriname; ${ }^{b}$ Biomed Institute, University of Hasselt, \\ Diepenbeek, Belgium
}

\section{Key Words}

Acute renal failure $\cdot$ Hypoxia $\cdot$ Isolated blood-perfused kidney $\cdot$ Mannitol $\cdot$ Rabbit kidneys $\cdot$

Transplantation

\begin{abstract}
Background/Aims: Hypoxia may play a role in the development of renal failure in donated kidneys. In the present study, the effects of hypoxia on isolated blood-perfused rabbit kidneys were investigated and the effects of mannitol were explored, giving special attention to intratubular pressure. Methods: Kidneys were perfused with their autologous blood during four 30min periods (P1-P4). P1 was considered baseline function. In P2, hypoxia was induced either alone or with an infusion of mannitol (15 mg/min) during P2-P4. Reoxygenation was applied after P2. Proximal intratubular pressure was measured in all conditions. Results: During hypoxia, renal blood flow doubled and restored immediately in P3. Urine flow stopped in P2, except in the series with mannitol, but gradually resumed in P3 and P4. Likewise, creatinine clearance recovered slightly $(<25 \%)$ in $\mathrm{P} 4$, except for the series with mannitol, where it still could be measured in P2 and reached a value $>50 \%$ of P1. Proximal intratubular pressure (mean \pm SD) increased from $12 \pm 5$ in $\mathrm{P} 1$ to $24 \pm 11 \mathrm{~mm} \mathrm{Hg}$ during hypoxia and returned to $10 \pm 6 \mathrm{~mm} \mathrm{Hg}$ in P3. This increase was not observed with mannitol. Conclusion: Cellular swelling might be responsible for the suppressed filtration during hypoxia and can be prevented by mannitol.
\end{abstract}

Copyright $\odot 2011$ S. Karger AG, Basel 


\section{Introduction}

Ischemic injury remains a problem in transplanted kidneys from donors after cardiac death, despite major progression in techniques and preventive therapies $[1,2]$. Regardless of an extensive insight into how hypoxia plays a central role in the development of renal cell failure and death [3], the pathophysiological mechanisms involved in the functional decline of the whole organ, eventually leading to a complete recovery or a definite failure, remain not fully explained.

The interdependence of organs requires that the experimental study of the renal function be dissociated from extrarenal control mechanisms. One of the principal reasons to develop and improve isolated kidney models was that in vivo studies are often complicated by concurrent changes in blood pressure, circulating fluid volume, $\mathrm{CO}_{2}$ tension, or neurogenic and hormonal responses to the experimental stimuli [4]. Moreover, the isolated perfused kidney can be subjected to a wide range of variables, which would be impossible in an in vivo model. For instance, the delivery of oxygen to the kidney can be reduced to very low levels, without the interference of compensatory responses from other organ systems, like the autonomic nervous system [5].

In the past, many studies evaluating the effects of hypoxic stress on isolated perfused kidneys have been performed with cell-free perfusate media, resulting in a poor-performing urinary concentration function [6]. The use of isolated kidneys perfused with blood has a number of advantages, such as the ability to concentrate the urine, a better filtration fraction and especially an improved delivery of oxygen to the inner medullary regions, preventing premature necrosis and dysfunction of this area [7]. Functional impairment in this model can be induced either by stopping the perfusate (ischemia) or by reducing oxygen tension of erythrocytes with continuous perfusion of the kidney. The latter condition might be more representative of human acute kidney injury, i.e. when blood flow is reduced due to very low blood pressure. The disadvantage of total blood flow cessation is the fact that it prevents the metabolic products of the ischemic kidney from being washed out.

Previously, our group has described a technique for the perfusion of an isolated rabbit kidney with autologous blood. In this experimental setup, the kidney shows a fairly normal

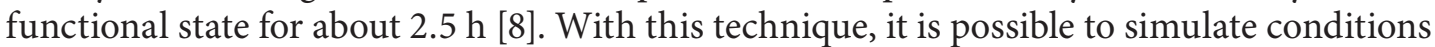
of a kidney to be transplanted and to investigate the influences of different substances on kidney function during hypoxia and reoxygenation.

Several pharmacological agents have been tried out in order to improve renal function after ischemic insults. Among these, mannitol, an osmotic diuretic, has been proven to be beneficial in transplantation [9]. Its main protective effect on postischemic kidneys has been proposed to be cell swelling [10]. Therefore, in this study, intratubular pressure measurements were used to investigate the effects of hypoxia on isolated rabbit kidneys, perfused with autologous blood, and to determine whether prevention of intratubular pressure increase by inhibiting cellular swelling thanks to hypertonic mannitol could indeed explain the improvement in renal function.

\section{Materials and Methods}

\section{Surgery and Perfusion}

The left kidney of female rabbits weighing 3-4 kg was removed under anesthesia (ketamine, $3-10 \mathrm{mg} / \mathrm{kg}$ of body weight) and perfused with a small amount $(25 \mathrm{ml})$ of heparinized blood from the same animal in a closed circuit including a pump and an oxygenator. It is important to mention that the turning cylinder, which allows the venous blood to form a fine film 
for the gas exchange, should be thoroughly cleaned with ether and alcohol before the start of the experiments; otherwise no thin blood film is formed over the total surface of the cylinder, resulting in poor gas exchange. The complete circulatory device was kept in a temperaturecontrolled bath at $38^{\circ} \mathrm{C}$, and warm oil or saline at the same temperature was dripped on the kidney surface [8]. In brief, the duration of the operative ischemia averaged $5 \mathrm{~min}$. Renal blood flow (RBF; Skalar Transflow 600 System, extracorporeal probe, internal diameter $3 \mathrm{~mm}$ ) and perfusion pressure (Gould Statham pressure transducer: P23 ID) were continuously monitored and recorded on a PC via a PowerLab 4E analog digital converter (ADInstruments). The perfusion pressure was kept constant at $100 \mathrm{~mm} \mathrm{Hg}$ through adaptation of the pumping device.

Urine was collected from a ureteral catheter. During the perfusion, continuous infusion was given $(0.1 \mathrm{ml} / \mathrm{min})$ in order to compensate for urine excretion. The content of the infusion solution (in mM) was: $\mathrm{NaCl} 35, \mathrm{KCl} 40$, creatinine 7.4, urea 133, $\mathrm{NaH}_{2} \mathrm{PO}_{4} 3.4, \mathrm{Na}_{2} \mathrm{HPO}_{4}$ 13.6, $\mathrm{NaHCO}_{3}$ 22.6, glutamine 10, and glucose 55. In addition, it also contained $30 \mathrm{IU} / 1$ [ $\mathrm{Arg}^{8}$ ]-vasopressin (AVP; Sigma). When urine flow (UF) exceeded $0.1 \mathrm{ml} / \mathrm{min}$, additional $\mathrm{NaCl}(145-290 \mathrm{mM})$ was infused to compensate for the excess urine production and loss of osmolytes. Blood loss through sampling and bleeding was compensated with a similar amount of whole blood in order to keep the hematocrit fairly constant at $32 \pm 3 \%$. The total amount of blood in the system should not exceed $25 \mathrm{ml}$, in order not to induce an irreversible intense vasoconstriction $[8,11]$.

After establishment of the perfusion, the isolated kidneys were allowed to recover for a period of at least $25 \mathrm{~min}$. This initial recovery was followed by four 30 -min periods of perfusion during which urine was collected (P1-P4). Blood samples were taken at the end of each period. The data recorded in P1 were used as reference values.

\section{Experimental Protocols}

In the first series of experiments $(\mathrm{n}=5)$, oxygen $\left(96 \% \mathrm{O}_{2}, 4 \% \mathrm{CO}_{2}\right)$ supply to the oxygenator was interrupted at the end of $\mathrm{P} 1$ and replaced by nitrogen $\left(96 \% \mathrm{~N}_{2}, 4 \% \mathrm{CO}_{2}\right)$, which was administered during the whole period P2 (25-30 min) and resulted in a decrease in arterial blood $\mathrm{PO}_{2}$ from $144 \pm 36$ to $11 \pm 3 \mathrm{~mm} \mathrm{Hg}(\mathrm{n}=5)$.

In the second series of experiments $(n=5)$, the renal perfusion conditions were similar to those of the previous hypoxic series. However, in this series, mannitol (15\%) was added to the compensating infusion at the start of $\mathrm{P} 2$ and continued in $\mathrm{P} 3$ and $\mathrm{P} 4$. One control series of experiments $(n=5)$ was carried out in which mannitol was evaluated for its functional effects on the perfused kidney during continuous normal perfusion without any other intervention. Mannitol was infused at the above-mentioned dose, starting at the beginning of P2. In all series, the hydrostatic pressure was measured in micropunctured proximal tubules using a servo-nulling micropressure system (model 900A; WPI) according to the technique of Fein [12] and Wiederhielm et al. [13]. Several proximal tubules were selected on their morphological aspects via a stereomicroscope (Leica MZ6) during each perfusion period. During pressure measurements, kidneys were superfused with a warm aqueous $0.9 \% \mathrm{NaCl}$ solution.

\section{Chemicals and Animals}

All chemicals were purchased from Sigma Belgium and were of the highest grade available. White adult rabbits were kept in the animal facilities of the University. Handling of animals was completely in accordance with the institutional ethical guidelines and rules.

\section{Analyses}

Plasma and urine samples were analyzed for $\mathrm{Na}^{+}, \mathrm{K}^{+}$and creatinine by a Beckman Synchron Clinical System CX3. Plasma and urine osmolality were measured with a Knauer-Halb micro-osmometer. Creatinine clearance $\left(\mathrm{C}_{\mathrm{Cr}}\right)$ was calculated as $C_{C r}=\left(U_{C r} \times U F\right) / P_{C r}$ where 
Table 1. Plasma potassium concentration and potassium excretion during P1-P4

\begin{tabular}{lcll}
\hline Period & Hypoxia & Hypoxia + mannitol & Mannitol \\
\hline Plasma $K^{+}, m E q / l$ & & \\
P1 & $3.1(0.8)$ & $2.7(0.4)$ & $2.8(0.3)$ \\
P2 & $4.7(1.0)^{*}$ & $6.4(1.7)^{*}$ & $2.2(0.4)$ \\
P3 & $7.2(0.7)^{*}$ & $6.2(2.1)^{*}$ & $1.8(0.4)^{*}$ \\
P4 & $4.2(0.6)$ & $1.9(0.8)$ & $1.7(0.3)^{*}$ \\
\hline \multicolumn{4}{l}{ excretion, $m E q / m i n \cdot g K W$} \\
P1 & $0.5(0.1)$ & $0.5(0.1)$ & $0.5(0.0)$ \\
P2 & - & $0.5(0.1)$ & $0.4(0.1)$ \\
P3 & $0.0(0.0)^{*}$ & $0.2(0.1)^{*}$ & $0.3(0.0)$ \\
P4 & $0.3(0.1)$ & $0.2(0.1)^{*}$ & $0.3(0.0)$ \\
\hline
\end{tabular}

Values are means $(\mathrm{SD}) .{ }^{*} \mathrm{p}<0.05$ vs. P1. KW $=$ Kidney weight.

$\mathrm{U}_{\mathrm{Cr}}$ and $\mathrm{P}_{\mathrm{Cr}}$ equal the urine and plasma concentrations of creatinine, and was used to estimate glomerular filtration rate (GFR). As was shown in a previous article [8], $\mathrm{C}_{\mathrm{Cr}}$ are similar to the inulin clearances found in vivo in hydrated rabbits [14]. $T^{C_{H_{2} O}}$ and $C_{\text {osm }}$ were calculated from UF and urine and plasma osmolality: $T^{C_{H_{2} \mathrm{O}}}=\left|C_{\text {osm }}-U F\right| . \mathrm{T}^{\mathrm{C}} \mathrm{H}_{2} \mathrm{O}$ was plotted against the $C_{o s m}$ in order to assess the concentrating ability of the kidneys [15]. pH, $\mathrm{PCO}_{2}$ and $\mathrm{PO}_{2}$ were measured with a Chiron Diagnostics $238 \mathrm{pH}$ /blood gas analyzer (Bayer).

\section{Histology}

In selected experiments, the kidney was fixed for histological examination at the end of perfusion. The arterial circulation was interrupted and about $15 \mathrm{ml}$ of formalin (6\%) were injected intra-arterially at a constant pressure of $100 \mathrm{~mm} \mathrm{Hg}$. The kidney was then cut into pieces and the pieces fixed further in formalin. Sections were stained with hematoxylineosin reagents and examined with the aid of a light microscope.

\section{Statistics}

The results are presented with their means and SD expressed per gram of kidney weight and were analyzed with one-way ANOVA followed by a Bonferroni test for multiple comparisons. $\mathrm{p}<0.05$ was considered as significantly different.

\section{Results}

During hypoxia (P2), RBF increased significantly (see experimental protocols) and recovered promptly after oxygenation was restored in P3 and P4 (blank and solid bars in fig. 1). Only a slight rise in RBF was observed during P2 when mannitol was given in the absence of hypoxia (gray bars in fig. 1a). Urine production was not measurable in P2 when hypoxia alone was applied. However, excretion of urine during hypoxia (P2) was still measurable with infusion of mannitol (fig. 2). In addition, $\mathrm{C}_{\mathrm{Cr}}$ decreased less with the infusion of mannitol (fig. 3) compared to the extensive decline in the series with hypoxia alone. $\mathrm{C}_{\mathrm{Cr}}$ almost reached the values obtained with mannitol alone. Sodium and potassium excretion decreased to zero during the hypoxic phase and recovered slightly after reoxygenation in conditions after plain hypoxia. With the addition of mannitol, sodium and potassium excretion remained fairly close to normal values (fig. 4; table 1). 
Fig. 1. a Average RBF of the four perfusion periods expressed per gram of kidney weight (KW). Blank bars = Hypoxia in P2; solid black bars = hypoxia in P2 and mannitol infusion during $\mathrm{P} 2-$ $\mathrm{P} 4$; gray bars = mannitol infusion during $\mathrm{P} 2-\mathrm{P} 4 .{ }^{*} \mathrm{p}<0.05$ vs. P1. b Representative tracing of RBF immediately before and during hypoxic stress. I = Stop oxygenation; II = blood sampling; III = restart oxygenation.
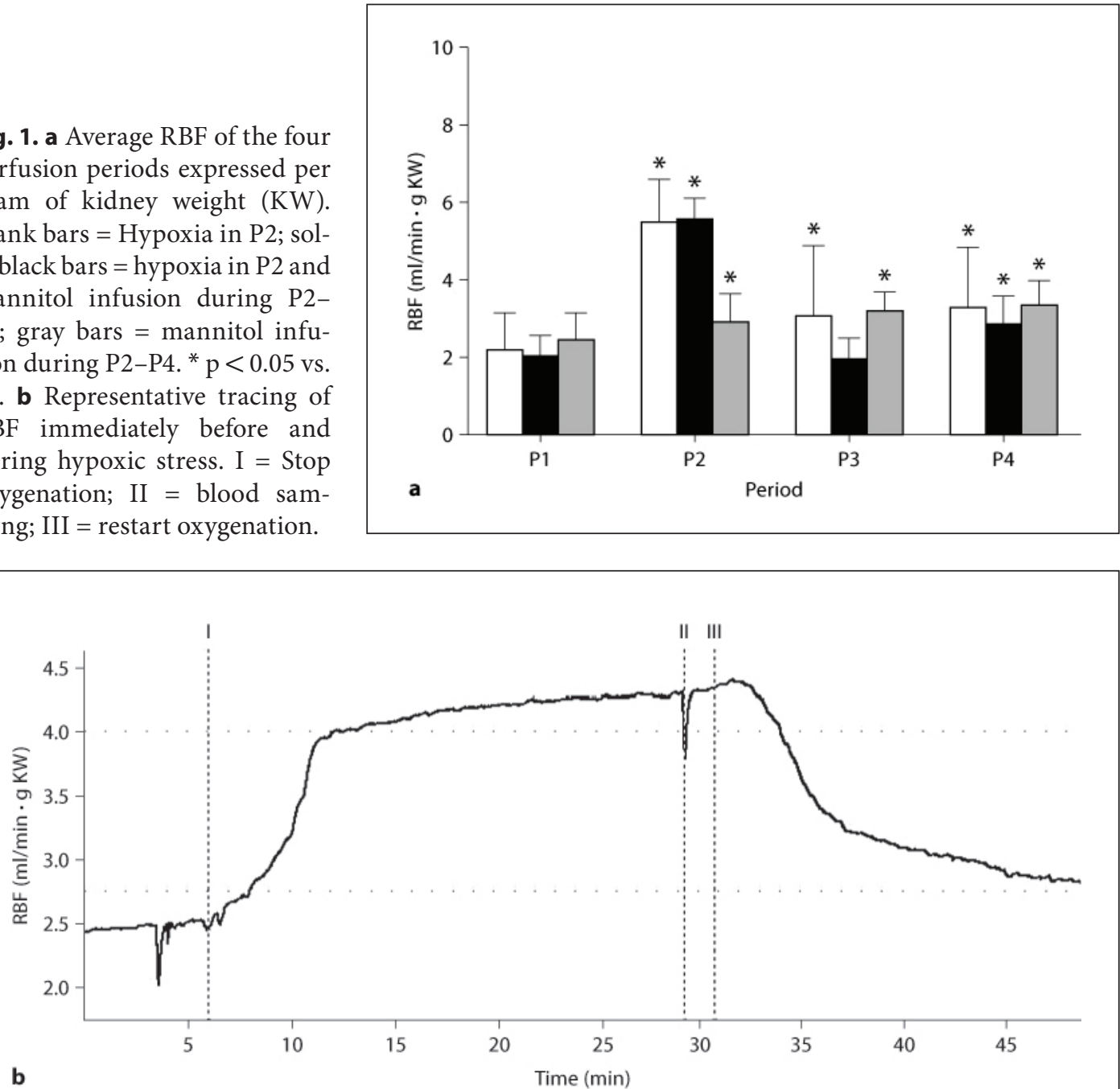

Fig. 2. UF expressed per gram of kidney weight (KW). UF ceased during hypoxia alone. Blank bars = Hypoxia in P2; solid black bars = hypoxia in P2 and mannitol infusion during $\mathrm{P} 2-\mathrm{P} 4$; gray bars $=$ mannitol infusion during $\mathrm{P} 2-\mathrm{P} 4 .{ }^{*} \mathrm{p}<0.05$ vs. $\mathrm{P} 1$.

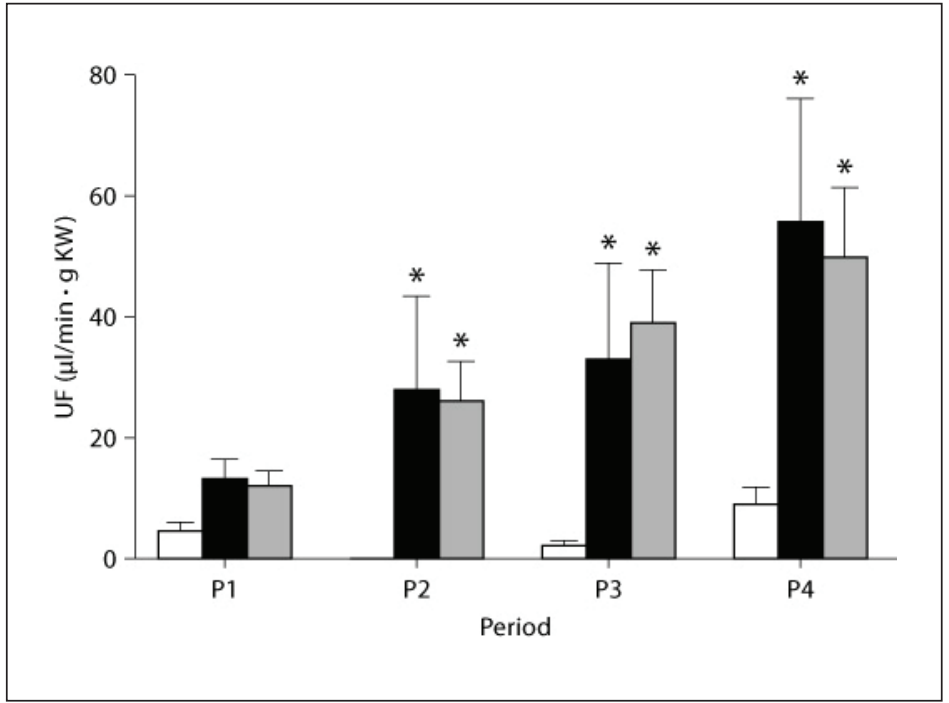


Fig. 3. $\mathrm{C}_{\mathrm{Cr}}$ expressed per gram of kidney weight (KW). Blank bars = Hypoxia in P2; solid black bars = hypoxia in P2 and mannitol infusion during P2-P4; gray bars $=$ mannitol infusion during $\mathrm{P} 2-\mathrm{P} 4$. ${ }^{*} \mathrm{p}<0.05$ vs. $\mathrm{P} 1$.

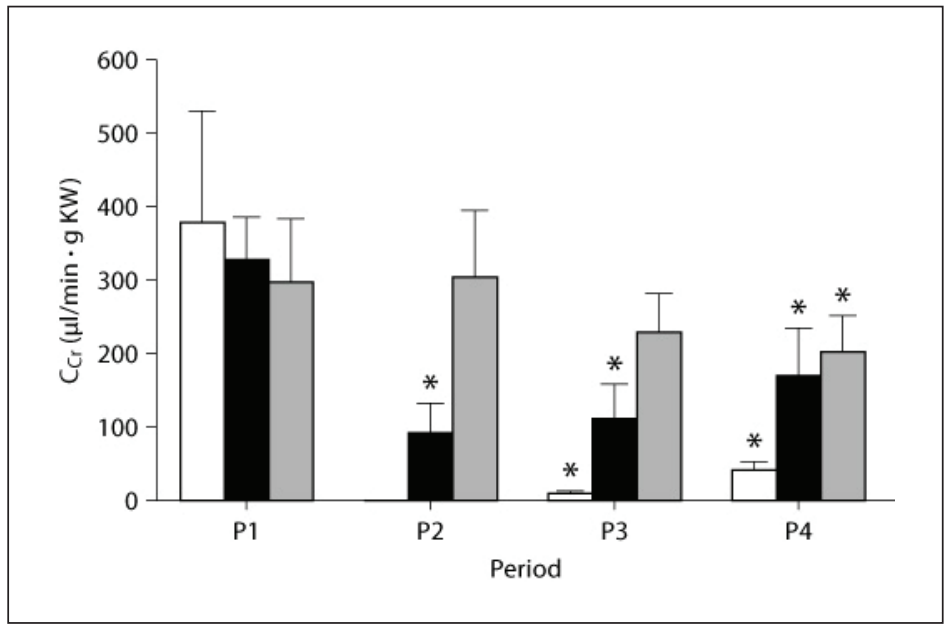

Fig. 4. Sodium excretion $\left(\mathrm{E}_{\mathrm{Na}}\right)$ expressed per gram of kidney weight $(\mathrm{KW})$. Blank bars = Hypoxia in P2; solid black bars = hypoxia in $\mathrm{P} 2$ and mannitol infusion during $\mathrm{P} 2-\mathrm{P} 4$; gray bars = mannitol infusion during $\mathrm{P} 2-\mathrm{P} 4$. ${ }^{*} \mathrm{p}<0.05$ vs. P1.

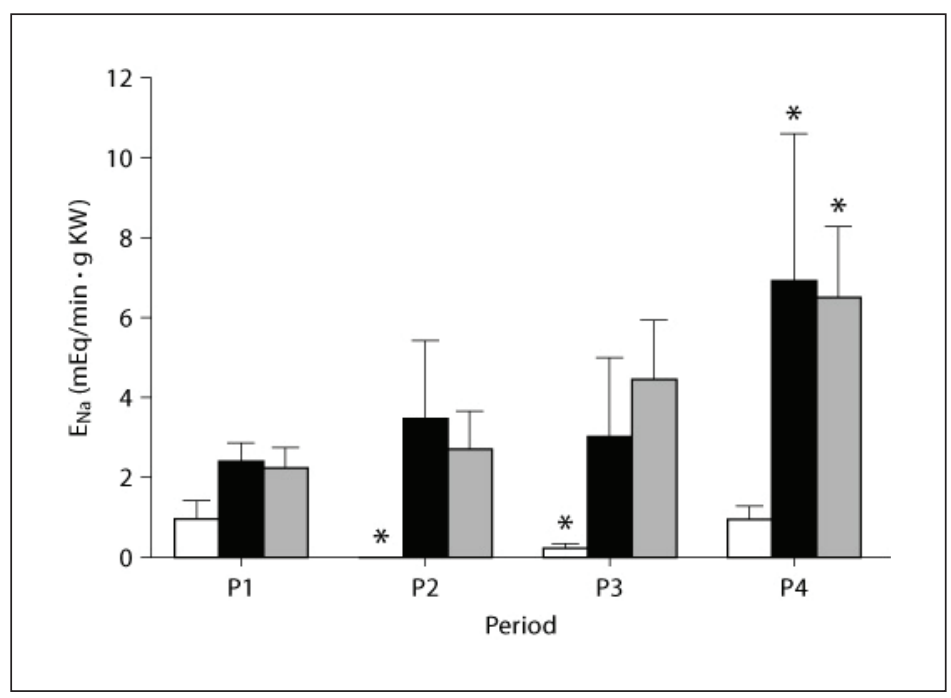

Plasma potassium concentration increased significantly in P2 and P3, with a slight restoration in $\mathrm{P} 4$, even in the presence of a reduced excretion in the series with a hypoxic insult (table 1). $\mathrm{T}^{\mathrm{C}}{ }_{\mathrm{H}_{2} \mathrm{O}}$ decreased after hypoxic stress. This decrease was significantly less when mannitol had been infused (fig. 5), indicating that $\mathrm{NaCl}$ was still being actively reabsorbed in the thick ascending limb of the loop of Henle. When $T^{C_{H_{2} \mathrm{O}}}$ is plotted against $\mathrm{C}_{\text {osm }}$, indicating how much 'free water' can be regained from the osmotic loss, it is obvious that during hypoxia the concentration capacity of the kidney is very low, whereas in the presence of mannitol that capacity seems independent of the hypoxic stress (fig. 6). In the absence of osmotic diuresis elicited by mannitol, the concentration capacity is optimal, as can be derived from the control data [15]. Plasma osmolality increased throughout the experiments in which mannitol was infused, both under normal and hypoxic conditions (table 2).

Proximal tubule pressure (PTP) increased during P2 under the hypoxic condition, except in the presence of mannitol, and recovered immediately to the initial value during P3 and P4 (fig. 7). PTP remained fairly constant in the series with mannitol alone.

Histological slides did not reveal any difference between hypoxic and normally perfused kidneys. 
Fig. 5. $T^{C} \mathrm{H}_{2} \mathrm{O}$ expressed per gram of kidney weight (KW). Blank bars = Hypoxia in P2; solid black bars = hypoxia in P2 and mannitol infusion during $\mathrm{P} 2-\mathrm{P} 4$; gray bars $=$ mannitol infusion during $\mathrm{P} 2-\mathrm{P} 4 .{ }^{*} \mathrm{p}<0.05$ vs. $\mathrm{P} 1$.

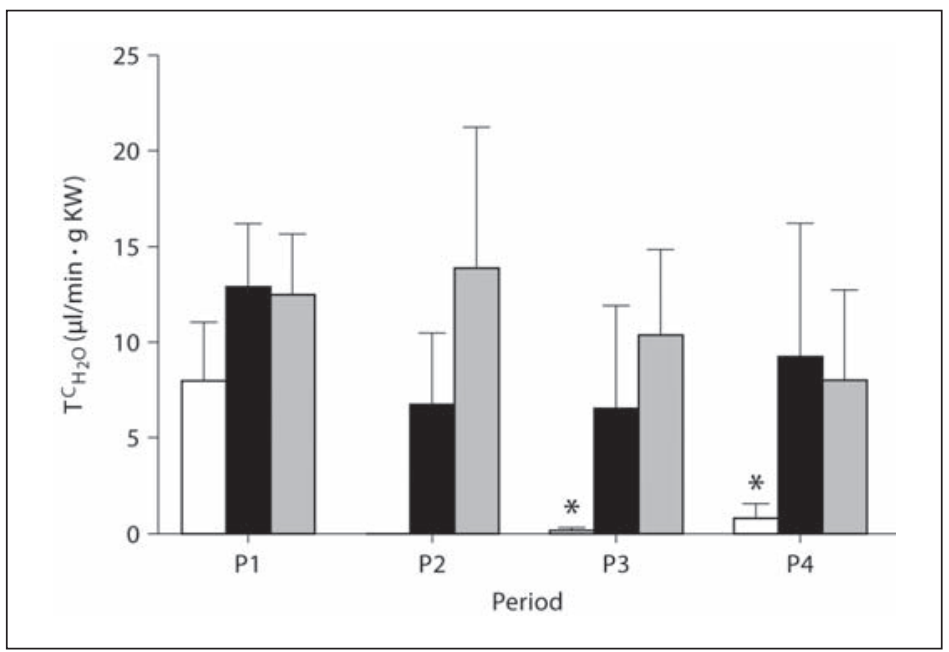

Fig. 6. $T^{\mathrm{C}} \mathrm{H}_{2} \mathrm{O}$ plotted against $\mathrm{C}_{\text {osm }}$ during normal perfusion $(\bigcirc)$, after hypoxia alone $(\diamond)$, during and after hypoxia and mannitol ( $\boldsymbol{\nabla})$, and during mannitol alone $(\bullet)$.

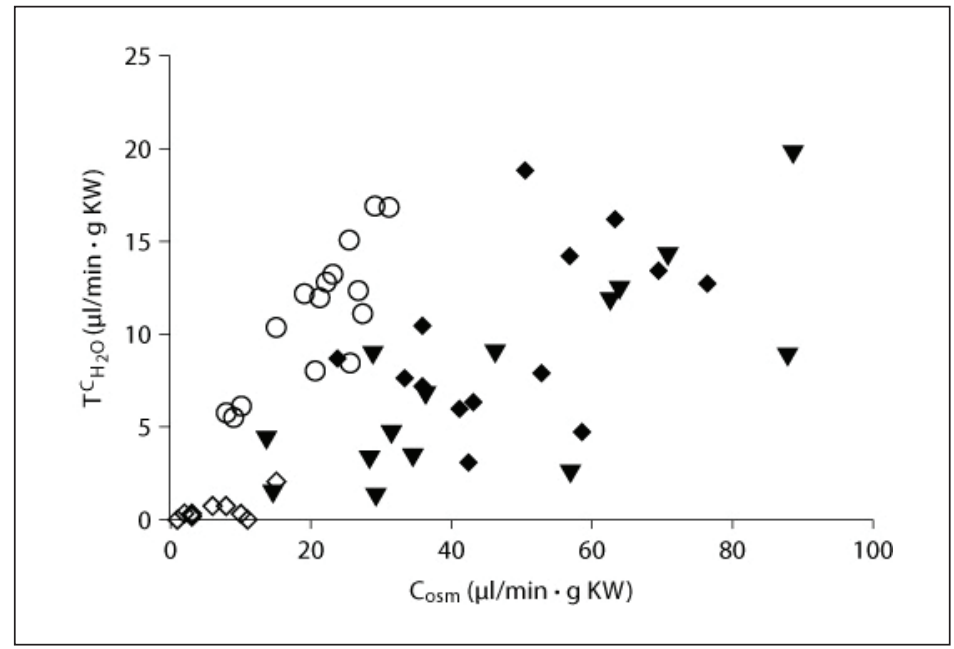

Fig. 7. PTP. Blank bars = Hypoxia in P2; solid black bars = hypoxia in P2 and mannitol infusion during $\mathrm{P} 2-\mathrm{P} 4$; gray bars = mannitol infusion during $\mathrm{P} 2-\mathrm{P} 4$. ${ }^{*} \mathrm{p}<0.05$ vs. P1.

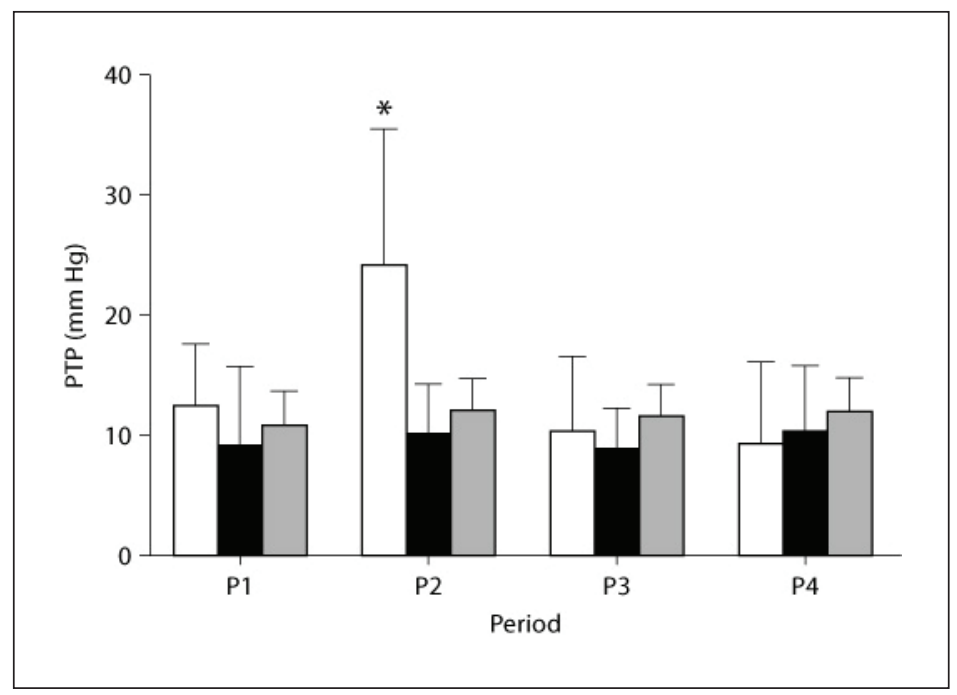


Table 2. Plasma osmolality in $\mathrm{P} 1-\mathrm{P} 4$

\begin{tabular}{llll}
\hline \multirow{2}{*}{ Period } & \multicolumn{3}{l}{ Plasma osmolality, mosm/l } \\
\cline { 2 - 4 } & hypoxia & hypoxia + mannitol & mannitol \\
\hline P1 & $275(12)$ & $303(10)$ & $295(10)$ \\
P2 & $272(14)$ & $322(9)$ & $304(17)$ \\
P3 & $278(12)$ & $373(8)^{*}$ & $336(15)^{*}$ \\
P4 & $282(13)^{*}$ & $396(33)^{*}$ & $360(17)^{*}$ \\
\hline
\end{tabular}

Values are means (SD). ${ }^{*} \mathrm{p}<0.05$ vs. $\mathrm{P} 1$.

\section{Discussion}

In this study, an attempt was made to investigate some aspects of the pathophysiology of hypoxic stress on an isolated rabbit kidney model perfused with autologous blood. The first striking observation was that during hypoxia, RBF increased more than twice the initial value, regardless of the constant perfusion pressure. With this increased RBF one would have expected a high $\mathrm{C}_{\mathrm{Cr}}$ [16], but on the contrary, urine production ceased. Moreover, the high $\mathrm{RBF}$ argues against any vascular obstruction during the hypoxic phase. In kidneys of newborn rabbits exposed to hypoxemia, an increase in renal vascular resistance was reported [17]. Besides the activation of the carotid bodies, in these studies mean blood pressure also decreased, which led to a reactive sympathetic stimulation and hence vasoconstriction. Our model is not influenced by the latter.

The corresponding PTP rise in parallel with the RBF during P2 may suggest that the cessation of urine production in $\mathrm{P} 2$ was a consequence of tubular obstruction $[18,19]$. This obstruction could be reversed by hypertonic mannitol infusion since it was observed that urine production did not entirely cease and in addition PTP did not increase during hypoxia in the presence of hypertonic mannitol, despite a similar increase in RBF. The possibility that the obstruction might be the result of extratubular compression by the peritubular capillaries is unlikely, since no rise in intratubular pressure was observed in the presence of mannitol during the hypoxic phase with an increased RBF. In the present preparation, the contribution of cast formation to the obstruction seems improbable. Indeed, then the obstruction would be mechanical and still be present after cessation of hypoxia, and intratubular pressure would have remained high during the recovery phase, as has been shown earlier [20]. In addition, histological examination of kidneys subjected to hypoxic insult did not reveal structural tissue damage compared with control kidneys. It is therefore assumed that reversible swelling of the tubular cells is the most probable cause of the obstruction, since this phenomenon was observed in MDCK cells exposed to metabolic inhibition [21] and in an experimental model of ischemic renal failure [22]. Moreover, in isolated rat kidneys perfused with artificial solutions with inherently lower oxygen content, it was reported that cortical tissue indicated signs of tubular epithelial swelling, whereas perfusion with hyperosmolar mannitol showed a well-preserved histology [23]. The increased plasma osmolalities, observed during infusion with hypertonic mannitol (table 2), support the suggestion that the cells are prevented from swelling during the hypoxic insult. The role of cellular swelling in kidney injury was also observed in a study in which hypertonic mannitol was able to reduce the effects of the injury at a comparable plasma osmolality, as achieved in the present study [24].

Finally, the increase in plasma potassium concentration during hypoxia, inducing the cellular potassium loss, and the subsequent decrease after reoxygenation, notwithstanding 
the decreased excretion in P3 and P4, indicate that the cells were still viable after the hypoxic insult and were able to restore their volume by activating the Na-K-ATPase. Moreover, the relatively high $\mathrm{T}_{\mathrm{H}_{2} \mathrm{O}}$ values during infusion of mannitol compared to plain hypoxia indicate that the Na pump in the thick ascending limb of the loop of Henle is still able to create an interstitial corticomedullary osmotic gradient, leading to free water reabsorption in the presence of vasopressin.

Since the partial oxygen pressure entering the kidney in our model is $11 \pm 3 \mathrm{~mm} \mathrm{Hg}$, we assume that it was $<5 \mathrm{~mm} \mathrm{Hg}$ in the vicinity of the tubules, for it was shown in a study on freshly isolated perfused proximal tubules of mice that electrogenic ion transport was maintained during a 20 -min exposure to hypoxic conditions of $5 \mathrm{~mm} \mathrm{Hg}$ and no swelling was observed [25].

The low $\mathrm{C}_{\mathrm{Cr}}$ in $\mathrm{P} 3$ and $\mathrm{P} 4$ cannot be explained by cell swelling, since intratubular pressure dropped to control values.

Mannitol leads to a better filtration during and after hypoxia, as has also been demonstrated earlier [26]. In a more recent study, mannitol decreased the delivery of $\mathrm{NaCl}$ to the distal segments of the nephrons [27]. This could contribute to an inhibition of the tubuloglomerular feedback [28]. The lower $\mathrm{NaCl}$ concentration at the level of the macula densa will depress the tubuloglomerular feedback mechanism responsible for the low filtration rate in the early recovery phase after reperfusion without mannitol. The RBF is not affected by mannitol, whereas GFR increases due to inhibition of the tubuloglomerular feedback mechanism. This can be explained by the fact that adenosine, the mediator of this mechanism, has a vasoconstrictor effect on the afferent glomerular arterioles via an $\mathrm{A}_{1}$ receptor, whereas the efferent arteriole dilates through $\mathrm{A}_{2}$ receptor activation, allowing a drop in GFR without affecting blood flow [29].

Mannitol was also protective in a reversible model of acute renal failure in dogs infused with norepinephrine through maintenance of glomerular capillary pressure and prevention of tubular obstruction [30].

In summary, the present results indicate that hypoxic stress leads to cellular swelling, which contributes to an obstruction of the tubular lumen, leading to an increase in tubular pressure and a decrease in GFR. Hypertonic mannitol reduces cellular swelling and probably inhibits the tubuloglomerular feedback, eventually leading to the improvement and even recovery of renal function during and after hypoxic stress. Mannitol may thus be beneficial for the function of posttransplanted kidneys when used cautiously by monitoring the osmolal gap and, as has been stated earlier, with an appropriate state of hydration $[9,31-33]$.

\section{Acknowledgments}

This research was supported by grants from the Ministry of Developmental Cooperation of the Kingdom of Belgium (ABOS-VZWK9601) and the Foundation for Scientific ResearchFlanders (FWO G0270.07).

Technical assistance was kindly provided by Wilfried Leyssens. A special word of thanks should go to Dr. Mikel Chan of the Department of Pathology of the Anton de Kom University of Suriname for his assistance in evaluating the histological findings.

\section{Disclosure Statement}

There was no conflict of interest by any author. 


\section{References}

1 Keizer KM, de Fijter JW, Haase-Kromwijk BJ, Weimar W: Non-heart-beating donor kidneys in the Netherlands: allocation and outcome of transplantation. Transplantation 2005;79:1195-1199.

2 Rao PS, Ojo A: The alphabet soup of kidney transplantation: SCD, DCD, ECD - fundamentals for the practicing nephrologist. Clin J Am Soc Nephrol 2009;4:1827-1831.

3 Rosenberger C, Rosen S, Heyman SN: Renal parenchymal oxygenation and hypoxia adaptation in acute kidney injury. Clin Exp Pharmacol Physiol 2006;33:980-988.

4 Ross BD: The isolated perfused rat kidney. Clin Sci Mol Med Suppl 1978;55:513-521.

5 Bursaux E, Poyart C, Bohn B: Renal hemodynamics and renal $\mathrm{O}_{2}$ uptake during hypoxia in the anesthetized rabbit. Pflugers Arch 1976;365:213-220.

6 Alcorn D, Emslie KR, Ross BD, Ryan GB, Tange JD: Selective distal nephron damage during isolated kidney perfusion. Kidney Int 1981;19:638-647.

7 Lieberthal W, Stephens GW, Wolf EF, Rennke HG, Vasilevsky ML, Valeri CR, Levinsky NG: Effect of erythrocytes on the function and morphology of the isolated perfused rat kidney. Ren Physiol 1987;10:14-24.

8 Cuypers Y, Vandenreyt I, Bipat R, Toelsie J, Van Damme B, Steels P: The functional state of the isolated rabbit kidney perfused with autologous blood. Pflugers Arch 2000;440:634-642.

9 Tiggeler RG, Berden JH, Hoitsma AJ, Koene RA: Prevention of acute tubular necrosis in cadaveric kidney transplantation by the combined use of mannitol and moderate hydration. Ann Surg 1985; 201:246-251.

10 Zager RA, Mahan J, Merola AJ: Effects of mannitol on the postischemic kidney. Biochemical, functional, and morphologic assessments. Lab Invest 1985;53:433-442.

11 Nizet A: The isolated perfused kidney: possibilities, limitations and results. Kidney Int 1975;7:1-11.

12 Fein H: Microdimensional pressure measurements in electrolytes. J Appl Physiol 1972;32:560-564.

13 Wiederhielm CA, Woodbury JW, Kirk S, Rushmer RF: Pulsatile pressures in the microcirculation of frog's mesentery. Am J Physiol 1964;207:173-176.

14 Laake H: Inulin clearance studies; concerning the cause of the reduced clearance figures in successive periods after one injection of inulin. Acta Med Scand 1954;148:135-146.

15 Barraclough MA, Guignard JP, Jones NF: Renal concentrating ability during hypertonic saline and mannitol diuresis in the rabbit. J Appl Physiol 1970;28:209-212.

16 Dworkin LD, Brenner BM: Biophysical basis of glomerular filtration; in Seldin D, Giebisch G (eds): The Kidney: Physiology and Pathophysiology. Philadelphia, Lippincott Williams \& Wilkins, 2000, pp 749-770.

17 Huet F, Gouyon JB, Guignard JP: Prevention of hypoxemia-induced renal dysfunction by perindoprilat in the rabbit. Life Sci 1997;61:2157-2165.

18 Mason J, Olbricht C, Takabatake T, Thurau K: The early phase of experimental acute renal failure. I. Intratubular pressure and obstruction. Pflugers Arch 1977;370:155-163.

19 Parekh N, Esslinger HU, Steinhausen M: Glomerular filtration and tubular reabsorption during anuria in postischemic acute renal failure. Kidney Int 1984;25:33-41.

20 Goligorsky MS, DiBona GF: Pathogenetic role of Arg-Gly-Asp-recognizing integrins in acute renal failure. Proc Natl Acad Sci USA 1993;90:5700-5704.

21 Baron S, Caplanusi A, van de Ven M, Radu M, Despa S, Lambrichts I, Ameloot M, Steels P, Smets I: Role of mitochondrial $\mathrm{Na}^{+}$concentration, measured by CoroNa red, in the protection of metabolically inhibited MDCK cells. J Am Soc Nephrol 2005;16:3490-3497.

22 Mason J, Joeris B, Welsch J, Kriz W: Vascular congestion in ischemic renal failure: the role of cell swelling. Miner Electrolyte Metab 1989;15:114-124.

23 Lindstrom KE, Ronnstedt L, Jaremko G, Haraldsson B: Physiological and morphological effects of perfusing isolated rat kidneys with hyperosmolal mannitol solutions. Acta Physiol Scand 1999;166: 231-238.

24 Flores J, DiBona DR, Beck CH, Leaf A: The role of cell swelling in ischemic renal damage and the protective effect of hypertonic solute. J Clin Invest 1972;51:118-126.

25 You Y, Hirsch DJ, Morgunov NS: Functional integrity of proximal tubule cells. Effects of hypoxia and ischemia. J Am Soc Nephrol 1992;3:965-974.

26 Lieberthal W, Sheridan AM, Valeri CR: Protective effect of atrial natriuretic factor and mannitol following renal ischemia. Am J Physiol 1990;258:F1266-F1272. 
27 Leyssac PP, Holstein-Rathlou NH, Skott O: Renal blood flow, early distal sodium, and plasma renin concentrations during osmotic diuresis. Am J Physiol Regul Integr Comp Physiol 2000;279:R1268R1276.

28 Alejandro V, Scandling JD Jr, Sibley RK, Dafoe D, Alfrey E, Deen W, Myers BD: Mechanisms of filtration failure during postischemic injury of the human kidney. A study of the reperfused renal allograft. J Clin Invest 1995;95:820-831.

29 Hansen PB, Schnermann J: Vasoconstrictor and vasodilator effects of adenosine in the kidney. Am J Physiol Renal Physiol 2003;285:F590-F599.

30 Burke TJ, Cronin RE, Duchin KL, Peterson LN, Schrier RW: Ischemia and tubule obstruction during acute renal failure in dogs: mannitol in protection. Am J Physiol 1980;238:F305-F314.

31 Lameire N, van Biesen W, Hoste E, Vanholder R: The prevention of acute kidney injury in an indepth narrative review. Part 2: Drugs in the prevention of acute kidney injury. NDT Plus 2009;2:1-10.

32 Schnuelle P, van der Woude FJ: Perioperative fluid management in renal transplantation: a narrative review of the literature. Transpl Int 2006;19:947-959.

33 Visweswaran P, Massin EK, Dubose TD Jr: Mannitol-induced acute renal failure. J Am Soc Nephrol 1997;8:1028-1033. 